\title{
Impact of Climate Change on Livestock, Various Adaptive and Mitigative Measures for Sustainable Livestock Production
}

\author{
Samir Das* \\ Principal Scientist, ICAR-Indian Veterinary Research Institute, India \\ *Corresponding author: Samir Das, Principal Scientist, ICAR- Indian Veterinary Research Institute, India

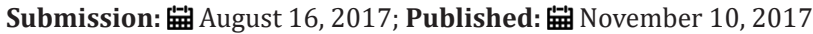

\section{Introduction}

Livestock is an integral part of agriculture in India as most of the people due to multifarious reasons depend on the livestock for their economic support. Climate Change poses formidable challenge to the development of livestock sector in India. The rise in temperature between 2 to $3{ }^{\circ} \mathrm{C}$ over the entire country together with increased humidity resulting from climate change is likely to aggravate the heat stress in dairy animals resulting in reduced growth and milk production. Due to rapid growth of human population, demand for milk and meat is increasing day by day. India possesses second largest number of cattle next to Brazil (13\% of world population), largest number of buffaloes (56\% of world population) in the world [1].

It is reported sporadically in different countries of the world including India that climate change has adverse effect on livestock productivity, particularly on milk production and growth which is reflected in meat production indirectly. St-Pierre et al. [2] estimated a total economic annual loss incurred by the US farm animals due to heat stress at between 1.69 to 2.36 billion US dollars. About $58 \%$ of this occurs in the dairy industry, $20 \%$ in the beef industry, $15 \%$ in pigs and the remaining 7\% in the poultry industry. Quantification of these potential impacts of climate on livestock production allows producers to gain a better understanding of the magnitude of the changes in production levels and potential indicators of livestock response, on which managemental actions depend. Economic losses resulting from temperature-induced reductions in production may justify adaptation and mitigation of adverse impact of climate change on animal.

\section{Impact of Climate Change on Livestock}

Domestic animals are homoeothermic which means that they must maintain their body temperature within a relatively narrow zone to remain healthy and productive. The ambient temperature above or below thermo neutral zone produces stress to the animal which ultimately hampers production, reproduction and growth. Four environmental factors which influence effective temperature: i. Air temperature,

ii. Relative humidity,

iii. Air movement and

iv. Solar radiation.

The temperature-humidity index (THI) is used commonly to indicate the degree of stress on dairy cattle. When the THI exceeds 74 , high producing dairy cows are affected adversely.

Livestock Weather Safety Index (LWSI) was developed to classify the combined intensity of temperature and humidity into four categories of THI values: THI less than or equal to 74 is Normal, THI 75-78 is Alert, THI 79-83 is Danger and THI value 84 and above is Emergency condition [3]. Experience over time suggested that the THI-based LWSI was a valuable tool for producers, even though it lacked recognition of the effects of thermal radiation and wind speed. Warnings, with respect to these categories, were issued by the United States Weather Bureau to alert producers to potential heat stress conditions.

Dairy cows respond to heat stress in several ways:

i. Reduced feed intake,

ii. Increased water intake,

iii. changed metabolic rate and maintenance requirements,

iv. Increased evaporative water loss,

v. Increased respiration rate,

vi. Changed blood hormone profile and

vii. Increased body temperature.

European-type cattle are considered to be comfortable in the temperature range of 5 to $20^{\circ} \mathrm{C}$, i.e., within this zone there is no heat stress problem. Body temperature is maintained with a minimum expenditure of energy, thus leaving a maximum portion 
of energy for productive processes. With increasing environmental heat load caused by high temperature, intensive solar radiation, high humidity, low air movement or a combination of several of these factors, defense mechanisms against overheating-sweating and panting come into operation. If cooling derived from these activities is insufficient, body temperature rises. This depresses appetite, which in turn reduces meat and milk production.

Berman [4] determined environmental threshold temperatures for dairy cows based on environmental factors and characteristics of the cows. Environmental factors included temperature, humidity, wind speed and direction, while cow characteristics included body weight, milk production level and hair coat colour. The threshold temperatures signaled when environmental intervention should begin in order to limit production loss. The ability to withstand heat varies considerably. Heat tolerance is low in young animals, in animals that are on a low level of feeding, in dehydrated, in high producing, and in non-acclimatized animals. It is also low in European-type cattle as compared with Indian type cattle. At a temperature of $29{ }^{\circ} \mathrm{C}$ and $40 \%$ relative humidity the milk yield of Holstein, Jersey and Brown Swiss cows was 93, 97, and 98\% of normal, but when relative humidity was increased to $90 \%$, yields were 69,75 , and $83 \%$ of normal respectively.

Hahn [5] reported the thermal comfort zone for optimum performance of adult cattle was $5-15^{\circ} \mathrm{C}$. However, no significant changes in feed intake and physiological processes were observed even upto $25^{\circ} \mathrm{C}$. However Dutt et al. [6] reported that in Indian condition upper temperature limit of comfort zone for maximum milk yield was $27^{\circ} \mathrm{C}$, about $2{ }^{\circ} \mathrm{C}$ higher than the same reported in temperate countries. This was due to adaptation of crossbred cows developed through crossing between indigenous cows with exotic bulls of Jersey, Brown Swiss and Holstein Friesian breed. Studies have shown that milk yield of crossbred cows were negatively correlated with THI [7]. The average daily milk yield of crossbred cows in the hot humid eastern part of the country was significantly reduced by rise of minimum temperature as rise in minimum temperature crossed the zone of thermo neutrality in cow [8]

It was observed that dry matter intake in cattle was declined with the increase of maximum temperature ( $\mathrm{T}$ max), temperature humidity index (THI) during hot summer and hot humid rainy season [9]. This was due to negative effect of high temperature on the appetite centre of hypothalamus. The influence of climatic conditions on milk production has also been observed in Haryana cows. The rising temperature decreased dry matter intake and milk yield [10]. The milk yield of Sahiwal cows also exhibited declining trend due to increase in temperature and relative humidity [11]. It was also reported that growth rate of crossbred cattle and buffaloes is more sensitive to rise in THI than Zebu cattle. Time to attain puberty was observed to prolong by 5-17 days due to decline in growth rate at high temperature.

\section{Impact on milk yield of cow}

Multiple regression analysis between the different micro climatological parameters and milk yield of cows maintained at divisional farm of the institute (ICAR Research Complex for Eastern Region, Patna) were done. It was observed that air temperature (AT), effective temperature (ET), temperature humidity index (THI) significantly $(\mathrm{P}<0.01)$ effect average daily milk yield, average weekly milk yield, average monthly milk yield, daily total milk yield of cows. However, relative humidity had highly significant $(\mathrm{P}<0.01)$ effect on average weekly milk yield and average monthly milk yield of cow. It was found that average daily milk yield, average weekly milk yield, average monthly milk yield, daily total milk yield of cows were reduced significantly $(\mathrm{P}<0.05)$ by $0.886,1.868,2.471$ and $4.375 \mathrm{~kg}$ respectively per unit increase of THI [12]. It was also observed that average weekly milk yield and average monthly milk yield were decreased significantly $(\mathrm{P}<0.05)$ by 0.062 and $0.069 \mathrm{~kg}$ respectively per $\%$ rise of relative humidity.

\section{Impact on different cardinal physiological reactions}

Data analysis revealed that there is significant effect due to the change of the micro climatological components on various cardinal physiological reactions i.e., rectal temperature, respiration rate and pulse rate of growing calves in different months. Overall mean rectal temperature, respiration rate and pulse rate during the period of study were $101.88^{\circ} \mathrm{F} \pm 0.07,30.74 \pm 1.11$ and $71.03 \pm 1.02$ respectively. Regression analysis revealed that AT and $\mathrm{RH}$ had significant $(\mathrm{P}<0.05)$ effect but THI and ET had highly significant $(\mathrm{P}<0.01)$ effect on the rectal temperature of calves [12]. All the micro climatological components had highly significant $(\mathrm{P}<0.01)$ effect on respiration rate. It was also observed that rectal temperature and respiration rate were increased significantly $(\mathrm{P}<0.05)$ per unit increase of AT, RH and THI [12].

\section{Impact on animal reproduction}

It is reported that the length and intensity of estrous period decrease, therefore less conception rate occurs. So heat stress may reduce the fertility of dairy cows in summer by poor expression of behavioural signs of oestrus due to a reduced estradiol secretion from the dominant follicle. In these situations the calving interval becomes longer. So lifetime production of dairy animal comes down. Heat stress during pregnancy slows down growth of the foetus due to decreased blood supply to the uterus which causes placental insufficiency to provide maternal nutrient, so leads to decreased fetal growth and calf size. Even there is early embryonic death in cows exposed to heat stress. Heat stress also leads to reduced seminal volume and sperm concentration. It is reported that ejaculate volume, concentration of spermatozoa and sperm motility in bulls are lower in summer than in winter season [13].

\section{Impact on egg and meat production in poultry}

The thermoregulation characteristics of poultry differ to some extent from those of mammals due to their high rate of metabolism associated with more intensive heat production and low heat dissipation capacity caused by their feathers and lack of sweat glands. Above $30^{\circ} \mathrm{C}$ the feed and energy intake declines to such an extent that birds are no more able to compensate for it, production declines rapidly and the rate of mortality increases. Several studies reported that high ambient temperatures decrease the digestibility 
of nutrients in poultry which might be due to reduced activity of trypsin, chymotrypsin, and amylase. Consequently, the lower and by most insufficient nutrient supply limits egg production, egg mass and shell quality of egg in layers, and the growth rate in broilers.

\section{Impact on feed and fodder production}

Shortage of feed and fodder to the tune of $40 \%$ dry fodder, $36 \%$ green fodder and $52 \%$ concentrate on dry matter basis and poor quality roughage, primarily crop residues, is already one of the major constraints in expression of full genetic potential in livestock production in India. Higher temperatures increase lignin formation in plant tissues and thereby reduce the digestibility and rates of degradation of fodder and crop residues in the ruminants. This will lead to reduced nutrient availability for animals and ultimately to a reduction in livestock production. So, in view of this situation of feed and fodder availability the adverse impact of climate change on crop production will further increase the gap between availability and requirement of feed and fodder.

\section{Impact on disease incidence}

It is reported that increased milk somatic cell counts and a high incidence of clinical mastitis in dairy cattle occur during hot summer months. Reduction of thermal stress by air conditioning or shade management resulted in a lower frequency of clinical mastitis in cows than those exposed to their natural environments. Singh et al. [14] reported higher incidence of clinical mastitis in dairy animals during hot and humid weather due to increased heat stress and greater fly population associated with hot-humid conditions. Kumar et al. [15] reported that the hot-humid weather conditions were found to aggravate the infestation of cattle ticks like, Boophilus microplus, Haemaphysalis bispinosa and Hyalomma anatolicum which act as vector for various protozoan diseases.

\section{Various Adaptative and Mitigative Measures for Sustainable Livestock Production}

\section{Adaptation by housing and managemental intervention}

Adaptation with reference to climate change is referred to as adjustment or preparation of natural, human or livestock systems to new or changing environment which moderates harm or uses beneficial opportunities. Adaptation can reduce the current risks of climate change impacts and can be used for addressing emerging risks. Dairy cattle production in hot climates may be improved in two ways:

i. By adapting the animal to the climate through selection, breeding and acclimatization,

ii. By adapting the climate to the animal by providing protective structures and cooling devices.

The first way poses a biological, the second a technical problem. For the solution of both these problems it is important to know the qualitative and quantitative responses of the animal to various degrees of heat stress. Promoting indigenous breeds for rearing as these are more heat tolerant than cross bred and exotic breeds. It was observed that adverse effect of heat stress such as reduction of milk yield was found to be least in indigenous cattle i.e., Sahiwal and Deoni than that of Jersey and Red Sindhi crosses.

Livestock management, in reality, is the manipulation of the animal environment to promote the most efficient production of meat, milk and wool. A better understanding of climatological stress and adaptations will greatly enhance managerial capabilities [16]. Several management practices are available to ameliorate heat stress, each with positive and negative properties. Housing provides the most potential control over environmental stressors; however, it comes at a relatively high initial investment cost per head.

Shade for livestock is considered essential to minimize loss in milk production and reproductive efficiency. Shades can improve animal comfort and productivity and should be designed to maximize ventilation and protection from the solar load. It is reported that well designed shade would reduce heat load on animal around $30-40 \%$. The design and management of shade for dairy cattle vary in different areas and climates. A shade space of 60 square feet per animal is considered adequate. The larger space allotments provide more open area for ventilation, which is a critical factor in hot, humid climate. Extensive comparisons of shade materials and the impact of roof size and orientation of shed on the micro-climate of shade were studied by different workers. Hay is proved to be suitable low cost roofing material for cattle shades. However, corrugated steel sheet is the most popular shade material because of its better durability and low maintenance requirements.

Das et al. [17] observed in a study that orientation of cattle shed has significant effect on microclimate of shed and milk yield of crossbred cow in coastal region. Cattle shades should be designed and orientated in such a way that the animals are exposed to a large proportion of the cool sky. The clear north sky acts as a cold sink. Hence, under an extremely hot, low rainfall (10 to $12 \mathrm{~cm}$ ) climate, an east-west orientation is preferable as the ground under the shade will remain cooler. An orientation with the long axis north and south will expose the area under the shade to the morning and afternoon sun and assist in keeping it dry. So, this type of orientation of shed is suitable in sub temperate to temperate climate of hilly region. The height for cattle shades would be 10 to $12 \mathrm{ft}$. The top of a shelter should be painted white, so as to reflect much of the incident solar radiation; the underside should be painted black, so as to reduce the radiant heat reflected from the ground onto the animals. Crops provide cooler surroundings for cattle shelter than bare ground. Tree plantation around the animal shed produces long term cooling effect on the animal.

Elimination of direct solar radiation is essential, since the radiated heat load imposed on an animal by the midday sun is several times greater than the metabolic heat generated by the animal. So reduction of indirect radiation to a minimum is needed to be achieved. This is achieved by the absence of objects, such as nearby buildings, heavy wooden fences etc, which absorb heat and radiate it onto the animals. False ceiling with low cost materials in the shed was proved in a study to reduce heat stress in cattle and buffalo [17]. 
Minimal interference with convective and evaporative heat loss from the animals, i.e., allowing natural air movement to carry heat and moisture away from the surface of the animals is very important. Ventilation system within livestock housing is very important factor and greatly affects the initial investment, energy consumption and cooling capacity. Cross ventilation is highly desirable to reduce heat load in animal shelter. So, increasing air movement with fans in the cattle shed, help to increase animal comfort and milk production. Fan should be fitted in cattle house @ one fan/25sq meter of space at a height of 8-9ft from the floor.

Evaporative cooling systems have improved the environment for lactating dairy cows in arid climates. These systems use high pressure, fine mist and large volumes of air to evaporate moisture and cool the air surrounding the cow. There are questions regarding the effectiveness of evaporative cooling systems in climates with high relative humidity because when relative humidity increases above $70 \%$, the potential reduction in $\mathrm{THI}$ is less than $10 \%$ [18].

Foggers disperse a very fine droplet of water which quickly evaporates, cools the surrounding air and raising the relative humidity. The design incorporates a ring of fogger nozzles attached to the exhaust side of the fan. As fog droplets are emitted they are immediately dispersed into fan's air stream where they soon evaporate. Animals are cooled as the cooled air is blown over their body and as they inspire the cooled air. Fogger systems are most effective in areas of low humidity. They are advantageous in the fact that they use less water (3-5 gallons/cow/day). Water filters must be cleaned or checked daily to prevent clogging of fogger nozzles. High pressure foggers should be used only in open-sided, ridge-vented, long shed. Small shed with side walls restrict air flow and evaporation of fog droplet. This reduces cooling and makes for excessively wet conditions in the barn [19].

In mist cooling system mister cool the air by same principle as fogger, animals are cooled primarily by inspiration of the cooled air, but a mist droplet is larger than a fog droplet. This system does not work well in windy conditions. In warm humid environments mist droplets are too large to fully evaporate and set on the ground The consequence is wet bedding and feed which are predisposing factors of various respiratory diseases. To achieve greater heat losses from animal surfaces, droplets of water must wet the hide, as it is the drying process from the animal's hide that removes heat from the animal. So, in a study it was observed that sprinkling of cold water on body surface of animal followed by air circulation by electric fans for an hour twice daily before milking was found to be very effective for reducing heat stress and increasing milk yield [19].

Modern technology can easily provide fully air conditioned animal houses thereby completely eliminating any heat stress problem. However, the cost of milk and meat produced in such way would in most instances is high [20]. It was reported that air conditioning in dairy shed for $24 \mathrm{~h} / \mathrm{d}$ improved milk yield by $9.6 \%$ in a subtropical environment. However, workout on cost of milk production indicated that air conditioning was not economical. New possibilities for cooling animals should be explored. An example for this line of approach is the cooling of animals by applying cooled air on their head and neck, a method tried out successfully by American workers. It was reported that zone-cooled cows (cooled air blown over the head and neck) produced on an average 19\% more milk yield than controls, although other scientists reported that it was not also economic [18].

Cooling pond effectively reduces body temperature in dairy cows. The primary mode of heat loss in cooling pond is conduction with a small amount lost by evaporative cooling after exiting the pond. Water temperature of the pond would be lesser than skin temperature of cow, thus a heat transfer gradient between the cow's body and the pond water was operative. This is common practice of reducing heat stress in buffalo and is called as wallowing. Availability of drinking water will eliminate the need for the animals to move into the sun for obtaining water. Moreover water should be available round the clock particularly in hot summer season. Handling of animals during peak temperature hours i.e., mid-day to late afternoon should be avoided to reduce heat stress.

Other species of domestic animals than cattle are faced with similar hot climate problems. They all benefit from an artificially cooled indoor climate. New ways should be sought for providing inexpensive hot climate shelters and for reducing the costs of artificial cooling, thus making environmental control an economically more efficient tool. A Livestock Safety Monitor (LSM) has been developed by Eigenberg et al. [3], to provide an early warning device to producers based on current weather conditions. The LSM uses current weather parameters of temperature, humidity, air speed and solar radiation to determine heat stress.

\section{Adaptation by nutritional intervention}

i. Take feed to cows, rather than cows to feed in hot weather. Walking to feed increases a cow's heat load, so reduce their walking during the hottest time of the day.

ii. Allow cattle grazing at night time in hot weather. So, night grazing may be practised for 2 -3hr to fulfill nutrient requirement partially and have sufficient exercise for normal physiological function.

iii. Highly digestible high-energy rations are an effective form of summer diet to help animals to control body temperature by reduction of excess heat. Providing cool drinking water and a low fiber diet renders comfort to the animals [21].

iv. Bypass fat was proved in a study to reduce heat stress in cattle and buffalo around 18-20\% [22].

v. Increase the concentration of minerals and vitamins in the diet to compensate for the reduction in feed intake, particularly sodium, potassium, magnesium and niacin levels in the diet. Supplementing cows with $1.5-1.6 \%$ DM of potassium and $0.5-0.6 \%$ DM of sodium will potentially improve milk yield in heat-stressed cows. Include magnesium at $0.35-0.4 \%$ DM to help to avoid metabolic problems (grass tetany) when feeding higher amounts of 
potassium. Including niacin $(6 \mathrm{~g} / \mathrm{cow} /$ day) may also be beneficial. It has been reported to reduce skin temperature and increase milk yield [23].

vi. Improvement in milk yield has also been reported by feeding $150-200 \mathrm{~g} / \mathrm{cow} /$ day of sodium bicarbonate during hot weather to help buffer the rumen.

vii. The use of antioxidants such as Vit. E, Vit. A and selenium helps in reducing the impact of heat stress by oxidant balance, resulting in improved reproductive efficiency and animal health [24].

\section{Adaptation by reproductive intervention}

i. Progesterone supplementation during early pregnancy has proven beneficial in some studies. Supplementation of exogenous progesterone during summer heat stress has the potential to improve fertility.

ii. Friedman et al. [25] reported that heat synchronization with GnRH and PGF2 $\alpha$ also improves fertility.

iii. The use of embryo transfer technology (ETT) is considered a potential strategy for minimizing the negative effects of heat stress on bovine reproduction [26].

\section{Contribution of Livestock to Climate Change}

The animal production system, which is vulnerable to climate change, is itself a large contributor to global warming through emission of methane and nitrous oxide. There are two sources of green house gas emissions from livestock: (a) From the digestive process: Methane is produced in herbivores as a by-product of 'enteric fermentation,' a digestive process by which carbohydrates are broken down by micro-organisms into simple molecules in the gut of the animal for absorption into the bloodstream. (b) From animal wastes: Animal wastes contain organic compounds such as carbohydrates and proteins. During the decomposition of livestock wastes under moist, oxygen free (anaerobic) environments, the anaerobic bacteria transform the carbon to methane [27].

Animal wastes also contain nitrogen in the form of various complex compounds. The microbial processes of nitrification and de-nitrification forms nitrous oxide, which is emitted to the atmosphere. India emerges as the largest contributor to the livestock methane budget, simply because of its enormous livestock population, although the emission rate per animal in the country was much lower than in the developed countries. For instance, the annual methane production per animal was estimated to be $95 \mathrm{~kg}$ for the dairy cows in Germany, nearly threefold higher than $35 \mathrm{~kg}$ for the Indian cattle [28]. The default enteric fermentation emission factors for cattle recommended by Inter-Governmental Panel on Climate Change [29] for national GHG inventories are also much higher for the developed countries compared to the Indian subcontinent.

The differences in per head emissions are due to lower level and poor quality of feed intake in India. Methane production in livestock is related to the level of intake and digestibility of feed. The livestock characteristics (age, weight and species), health and living conditions influence the energy requirement. Higher methane production results from higher energy requirement and feed intake. The energy requirement of Asian cattle species Bos indicus is about $10 \%$ lower than European and North American cattle species Bos taurus [30]. In Indian conditions the animals are mostly fed on poor quality roughages of low digestibility and emit less methane than exotic cattle of developed countries fed with highly digestible feed. The estimates of total enteric emissions from Indian livestock vary widely from 6.17 to 10.4 million tons/year [27].

\section{Approachs for mitigation}

Several mitigation options are available for methane emissions from livestock. In India, the possibility of capturing or preventing emissions from animal manure storage is limited as it is extensively used as fuel in the form of dry dung cakes. Hence, the scope of decreasing methane from livestock largely lies in improving rumen fermentation efficiency.

There are a number of nutritional technologies for improvement in rumen efficiency like, diet manipulation, direct inhibitors, feed additives, propionate enhancers, methane oxidisers, probiotics, defaunation and hormones [27]. Field experiments in India involving some of these options have shown encouraging results with reduction potential ranging from about 6 to 32\%. Dietary manipulation through increased green fodder decreased methane production by $5.7 \%$ [31]. There is lower methane production when higher amount of leguminous fodder is included in the diet due to lower crude fiber content, higher digestibility of leguminous fodder and the faster rate of passage through the digestive system [32]

Methane emissions may be reduced by feeding more concentrate and reducing the intake of forage. Increasing the concentrate in the diet of animals reduced methane by $15-32 \%$ depending on the level of concentrate in diet [31]. This is because the fraction of feed converted to methane decreases when feed quality improves [33]. Feed conversion efficiency is improved when animals are fed concentrates and growth rate improves. They reach slaughter weight sooner resulting in fewer emissions. The methane mitigation by molasses urea supplementation was $8.7 \%$ [34]. Methane production tends to be lower when forages are ensiled than when they are dried. It means that making silage of fodder enhances digestibility, so reduces methane production.

There are a number of feed additives that have been proposed for the reduction of methane emissions [32]. These are ionophores, antibiotics, halogenated compounds (condensed tannins, saponins or essential oils) and propionate precursors (fumarate and malate). Use of feed additives such as monensin could reduce methane emission by $21 \%$ [35]. Stimulation of propionate production could be the best alternative hydrogen sink to methane production in the rumen. Therefore a strategy for abatement of methane production should be considered with a strategy to enhance propionate production. 
Vaccines are being developed that contain an antigen derived from methanogenic bacteria and an immunogenic preparation that reduces the activity of rumen protozoa [36]. Bovine somatotropin (bST) and hormonal growth implants do not specifically suppress methane formation but improve the animal's performance and thereby reduce methane emissions [33]. In IVRI rumen manipulation was developed to improve fibre utilization and to reduce methane emission to the tune of $12 \%$ in cross-bred calves and $25 \%$ in buffalo. Culling of unproductive animals as far as possible would reduce methane production. Reducing unproductive livestock numbers could be the best possible solution in countries where there are large livestock populations (513 million livestock in India) and who want to reduce their livestock related green house gas emissions [32].

Enteric methane emission/kg dry matter intake has been observed to increase under severe heat. So, protection of animals from severe heat stress through proper housing and heat ameliorative measures will be effective in reducing methane emission. In India major amount of dung of cattle and buffalo and all faecal material of all other livestock species is used as manure in agricultural fields which does not undergo much of anaerobic fermentation. Share of GHG emissions from manure management system was only $8 \%$ of the global GHG emissions from manure management. Improvement in disposal of farm yard manure and its use for biogas production and use of biogas slurry in the field and in the pond as fish feed can reduce methane emission from manure. So, improved manure management i.e., biogas production would reduce methane emission [37].

\section{Conclusion}

Biometeorology has a key role in rational management to meet the challenges of thermal stress on livestock production systems. While the focus is primarily on cattle in warm or hot climates, the importance of dynamic animal responses to climatological changes applies to all species and climates. Animal housing and management is the high priority adaptation measure to minimize the effects of climate and climate change on livestock production. So climate resilient shed may be constructed at Govt. livestock farm for training and demonstration purpose. So, risk management, by considering perceived thermal challenges, then assessing the potential consequences and acting accordingly, will reduce the impact of climate changes.

\section{References}

1. FAO (2014) Food and Agriculture Organization of the United Nations, Rome, Italy.

2. St-Pierre NR, Cobanov B, Schnitkey G (2003) Economic Losses from Heat Stress by US Livestock Industries. J Dairy Sci 86(Suppl): 52-77.

3. Eigenberg RA, Brown-BTM, Nienaber JA (2007) Development of a livestock weather safety monitor for feedlot cattle. Applied Engineering in Agriculture 23(5): 657-660.

4. Berman A (2005) Estimates of heat stress relief needs for Holstein dairy cows. J Anim Sci 83(6): 1377-1384.

5. Hahn GL (1999) Dynamic responses of cattle to thermal heat loads. J Anim Sci 77(2): 10-20.
6. Dutt T, Taneja VK, Singh A, Singh A (1992) Comfort zone for maximal milk production in crossbred cattle. Indian J Dairy Sci 45(3): 119-122.

7. Mandal DK, Rao AVMS, Singh K, Singh SP (2002) Effects of macroclimatic factors on milk production in a Frieswal herd. Indian J Dairy Sci 55(3): 166-170.

8. Kale MM, Basu SB (1993) Effect of climate and breed on the milk production of crossbred cattle. Ind J Dairy Sci 46(3): 114-118.

9. Upadhaya RC, Singh SV, Kumar A, Gupta SK, Ashutosh A (2007) Impact of Climate change on Milk production of Murrah buffaloes. Italian J Animal Sci 6(2s): 1329-1332.

10. Lal SN, Verma DN, Husain KQ (1987) Effect of air temperature and humidity on the feed consumption, cardio respiratory response and milk production in Haryana cows. Indian Vet J 64 (2): 115-121.

11. Mandal DK, Rao AVMS, Singh K, Singh SP (2002) Comfortable macroclimatic conditions for optimum milk production in Sahiwal cows. J Appl Zool Res 13(2-3): 228-230.

12. Das SK (2012) Effect of THI on milk production and physiological responses of crossbred cows during different months under the agro climatic condition of Bihar. Indian J Dairy Sci 65(3): 246-248.

13. Samal L (2013) Heat Stress in Dairy Cows - Reproductive Problems and Control Measures. Int J Livest Res 3(3): 14-23.

14. Singh KB, Nauriyal DC, Oberoi MS, Baxi KK (1996) Studies on occurrence of clinical mastitis in relation to climatic factors. Indian J Dairy Sci 49(8): 534-536.

15. Kumar S, Prasad KD, Deb AR (2004) Seasonal prevalence of different ectoparasites infecting cattle and buffaloes. BAU J Res 16(1): 159-163.

16. Stott GH (1981) What is animal stress and how is it measured? J Anim Sci 52(1): 150-153.

17. Das SK, Karunakaran M, Barbuddhe SB, Singh NP (2015) Effect of Orientation, Ventilation, Floor Space Allowance and Cooling Arrangement on Milk Yield and Microclimate of Dairy Shed in Goa. J Anim Res 5(2): 231-235.

18. Collier RJ, Dahl GE, Van Baale MJ (2006) Major advances associated with environmental effects on dairy cattle. J Dairy Sci 89(4): 1244-1253.

19. Bucklin RA, Turner LW, Beede DK, Bray DR, Hemken RW (1991) Methods to relieve heat stress for dairy cows in hot, humid climates. Applied Engineering in Agriculture 7(2): 241-247.

20. Bianca W (1964) Animal Housing in Hot Countries. Int J Biometeorology 8(2): 99-101.

21. Beede DK, Collier RJ (1986) Potential nutritional strategies for intensively managed cattle during thermal stress. J Anim Sci 62(2): 543554 .

22. Terada F (1996) Milk production in hot and humid environments. In: Proceedings of the $8^{\text {th }}$ AAAP Animal Science Congress 1: 414-421.

23. West JW (2003) Effects of Heat-Stress on Production in Dairy Cattle. J Dairy Sci 86(6): 2131-2144.

24. Sejian V, Singh AK, Sahoo A, Naqvi SMK (2014) Effect of mineral mixture and antioxidant supplementation on growth, reproductive performance and adaptive capability of Malpura ewes subjected to heat stress. J Anim Physiol Anim Nutr (Berl) 98(1): 72-83.

25. Friedman E, Voet H, Reznikov D, Dagoni I, Roth Z (2011) Induction of successive follicular waves by gonadotropin-releasing hormone and prostaglandin F2 $\alpha$ to improve fertility of high producing cows during the summer and autumn. J Dairy Sci 94(5): 2393-2404.

26. Baruselli PS, Ferreira RM, Sales JN, Gimenes LU, Sá Filho MF, et al. (2011) Timed embryo transfer programs for management of donor and recipient cattle. J Theriogenology 76(9): 1583-1593.

27. Sirohi S, Michaelowa A (2007) Sufferer and cause: Indian livestock and 
climate change. Climatic Change 85(3-4): 285-298.

28. Crutzen PJ, Aselmann I, Seiler W (1986) Methane production by domestic animals, wild ruminants, other herbivorous fauna and humans. Tell us 38B(3-4): 271-284.

29. IPCC (2001) Technical summary: contribution of Working Group I to the Third Assessment Report. Intergovernmental Panel on Climate Change, January 2001.

30. NRC (1996) Nutrient requirement of beef cattle. National Research Council, National Academy Press, Washington, DC, USA.

31. Singhal KK, Mohini M (2002) Uncertainty reduction in methane and nitrous oxide gases emission from livestock in India. Project report of Dairy Cattle Nutrition Division, National Dairy Research Institute, Karnal, India, p. 62.

32. Indira D, Srividya G (2012) Reducing the Livestock related green house gases emission. Vet World 5(4): 244-247.

33. Garnett $T$ (2007) Meat and Dairy production and consumption:
Exploring the livestock sector's contribution to the UK's green house gas emissions and assessing what less green house gas intensive systems of production and consumption might look like food. Climate research Network.

34. Srivastava AK, Garg MR (2002) Use of sulfur hexafluroide tracer technique for measurement of methane emission from ruminants. Indian J Dairy Sci 55(1): 36-39.

35. De D, Singh GP (2001) Monensin enriches UMMP supplementation on in vitro methane production in crossbred calves. In: Proceedings of the $\mathrm{X}$ Animal Nutritional Conference), Karnal, India.

36. Sejian V, Lal R, Lakritz J, Ezeji T (2010) Measurement and prediction of enteric methane emission. Int J Biometeorol 55(1): 1-16.

37. Suriyasathaporn W, Boonyayatra S, Kreausukon K, Pinyopummintr T, Heuer C (2006) Modification of Microclimate to Improve Milk Production in Tropical Rainforest of Thailand. Asian - Aust. J Anim Sci 19(6): 811-815. 